\title{
Not that innocent - ammonium ions boost homogeneous light-driven hydrogen evolution
}

\author{
Magdalena Heiland, ${ }^{a}$ Ratnadip De, ${ }^{b, c}$ Sven Rau, ${ }^{* a}$ Benjamin Dietzek-Ivansic, ${ }^{* b, c}$ Carsten Streb*a
}

a. Institute of Inorganic Chemistry I, Ulm University, Albert-Einstein-Allee 11, 89081 Ulm, Germany

E-mail: sven.rau@uni-ulm.de; carsten.streb@uni-ulm.de

b. Institute of Physical Chemistry, Friedrich Schiller University Jena, Helmholtzweg 4, 07743 Jena, Germany

E-mail: benjamin.dietzek@uni-jena.de

c. Leibniz Institute of Photonic Technologies (IPHT), Albert-Einstein-Straße 9, 07745 Jena, Germany

\begin{abstract}
We report that the homogeneous light-driven hydrogen evolution reaction (HER) can be significantly enhanced by the presence of seemingly innocent ammonium $\left(\mathrm{NH}_{4}{ }^{+}\right)$cations. Expermiental studies with different catalysts, photosensitizers and electron donors show this to be a general effect. Preliminary photophysical and mechanistic studies provide initial suggestions regarding the role of ammonium in the HER enhancement.
\end{abstract}

The conversion of solar energy into storable fuels, such as hydrogen, is a central concept to overcome diurnal and seasonal effects in solar radiation flux. ${ }^{1-5}$ Using sunlight to drive the splitting of water into oxygen and hydrogen is one of the most straight-forward reactions to this end. However, both halfreactions, i.e. the light-driven oxygen evolution reaction (OER) and the light-driven hydrogen evolution reaction (HER) are still formidable chemical challenges and require catalysts which are highly active, stable and economically viable. ${ }^{6}$

Molecular light-driven HER catalysis is a thriving field of research, as understanding the complex mechanisms and interactions which control HER activity can provide valuable insights for advanced component design. While early studies were focused on noble-metal (e.g. Pt) complexes as HER catalysts, 7,8 recent research has explored earth-abundant metal complex HER-catalysts, e.g. based on iron, ${ }^{9-12}$ cobalt $^{13,14}$ or nickel ${ }^{15}$ as reaction sites. In addition, molybdenum sulfide complexes, or thiomolybdates, have recently received widespread attention as they show high HER activity under homogeneous light-driven and heterogeneous (photo-) electrocatalytic conditions. ${ }^{16}$ In addition, they are considered viable molecular models for amorphous molybdenum sulfide HER catalysts. ${ }^{16,17}$

Typically, homogeneous light-driven HER systems feature three key components: a photosensitizer (PS) for light-harvesting, charge-separation and electron-transfer, a catalyst (CAT) for the catalytic hydrogen evolution, and a sacrificial electron donor (SED) to provide reduction equivalents for re-generating the
PS. ${ }^{2,7,18}$ The overall HER activity is not only controlled by the interplay of these species, but depends on the solvent, solution $\mathrm{pH}$ (or proton concentration, in organic solvents) and other factors, which are typically screened in initial catalytic optimization studies to identify ideal operating conditions. The impact of this complex set of experimental variables on the HER performance observed is often difficult to rationalize. ${ }^{19}$

This challenge can be illustrated by studies which explored the complex reactivity in a HER model system containing the sacrificial electron donor ascorbic acid/ascorbate, and model PS based on $\left[\mathrm{Ru}^{\prime \prime}(\mathrm{bpy})_{3}\right]^{2+}$ (bpy $=2,2^{\prime}$-bipyridine) or derivatives thereof. The following examples follow a common initial mechanism, where the photoexcited PS* is reductively quenched by the SED. Subsequently, the reduced PS ${ }^{--}$transfers an electron to the CAT, see Figure 1.

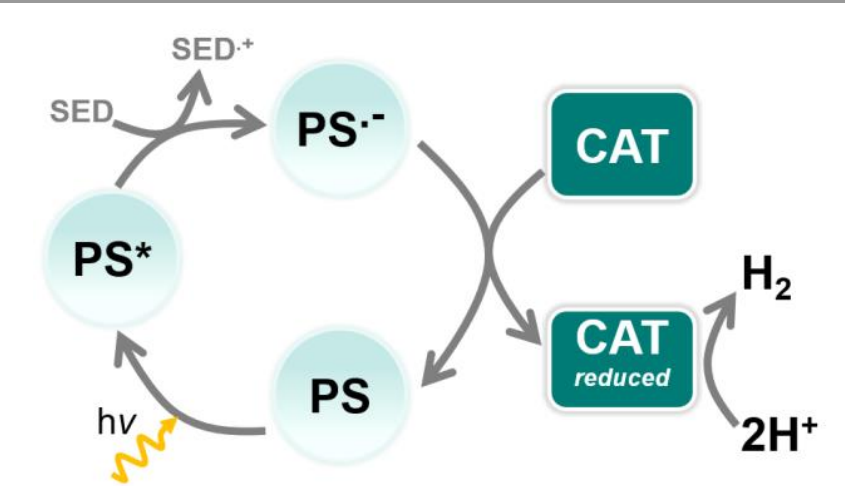

Figure 1: Simplified schematic illustration of a homogeneous, three molecular component HER setup, and the typical light-induced electron-transfer steps from sacrificial electron donor (SED) to photosensitizer (PS) and catalyst (CAT).

In this seemingly straight-forward set of reactions, unexpected effects of supposedly "innocent" (i.e., not participating in the reaction) spectator species have been described: In 2014 Scandola and colleagues demonstrated, that dehydroascorbic acid (DHA), which is the 2-proton/2-electron oxidation product 
of the SED ascorbic acid/ascorbate, inhibits light-driven HER catalysis due to highly efficient quenching of the reduced PS ${ }^{--}$ (i.e. $\left.\left[\mathrm{Ru}(\mathrm{bpy})_{3}\right]^{+}\right) .{ }^{20}$ In consequence, as HER catalysis proceeds, the DHA concentration increases and the reactivity-limiting effect of DHA becomes more dominant. Thus, deliberate decrease of the DHA concentration (by re-reduction to ascorbate) has been proven to result in increased light-driven HER performance. ${ }^{21}$ Intriguing $\mathrm{pH}$ effects were reported by Durrant and co-workers. ${ }^{22}$ The group investigated the $\mathrm{pH}$ optimum for the light-driven HER by the PS $\left[\mathrm{Ru}(\mathrm{bpy})_{3}\right]^{2+}$ and a Ni-phosphine catalyst. Photophysical and catalytic studies showed that the PS operates best at less acidic $\mathrm{pH}$ (due to a more efficient PS quenching by the SED ascorbate compared with ascorbic acid, Figure 1), while the catalyst operates best at acidic $\mathrm{pH}$, as protonation is required for efficient HER. Thus, an intermediate $\mathrm{pH}$ had to be chosen as compromise for optimum HER performance.

Related studies also demonstrated that optimum catalytic HER performance is based on an intricate interplay between the PS:CAT:SED ratios, and theoretical prediction of the optimum performance ranges is currently nearly impossible, as the underlying interactions between these species, and their effect on HER are often unknown. ${ }^{23-26}$

Here, we report an unexpected reactivity-enhancing effect of ammonium $\left(\mathrm{NH}_{4}{ }^{+}\right)$ions in light-driven, homogeneous HER catalysis. This effect is observed for a range of metal complex PS and metal complex CAT combinations in different solvents, suggesting that it is of a rather general nature. Preliminary mechanistic catalytic and photophysical studies provide initial insights into some of the underlying effects of the ammonium ions in one model reaction system.

Initial experiments explored the catalytic performance of the light-driven HER in the system PS: $\left[\mathrm{Ru}(\mathrm{bpy})_{3}\right]^{2+}(=\mathrm{Ru}-\mathrm{PS} ; 20 \mu \mathrm{M})$; CAT: $\left[\mathrm{Mo}_{3} \mathrm{~S}_{13}\right]^{2-}\left(=\left\{\mathrm{Mo}_{3}\right\} ; 0.3 \mu \mathrm{M}\right) ; \mathrm{SED}$ : ascorbic acid/ascorbate (10 mM); solvent: $\mathrm{MeOH}: \mathrm{H}_{2} \mathrm{O}(9: 1, \mathrm{v}: \mathrm{v})$, light source: LED $\left(\lambda_{\max }=\right.$ $\left.470 \mathrm{~nm}, P \sim 40 \mathrm{~mW} / \mathrm{cm}^{2}\right) \cdot 16,27,28$ These experiments showed major reactivity differences depending on the type of alkaline aqueous solution used to adjust the reaction $\mathrm{pH}$ (to $\mathrm{pH} 6$ ). When an aqueous tetraethylammonium hydroxide $\left(\mathrm{Et}_{4} \mathrm{NOH}\right)$ solution was used for $\mathrm{pH}$ adjustment, very low hydrogen evolution was observed after $6 \mathrm{~h}$ irradiation (TON 260, Fig. 2A and Table 1). In contrast, when aqueous ammonium hydroxide $\left(\mathrm{NH}_{4} \mathrm{OH}\right)$ solution was used for $\mathrm{pH}$ adjustment, we noted significant $\mathrm{HER}$ activity, reaching TONs of $\sim 6,600$ after $t_{\text {irradiation }}=6 \mathrm{~h}$ (Figure $2 \mathrm{~A}$ and Table 1 ), which is an increase by a factor of $\sim 25$. We could also show, that increasing concentrations of ammonium in the reaction medium (whilst maintaining the $\mathrm{pH}$ at $\mathrm{pH}=6$, due to the ascorbic acid/ascorbate buffering effect) results in increasing HER activity (Figure $2 \mathrm{~B}$ ).

This startling observation led us to study the use of other amine bases featuring $\mathrm{N}-\mathrm{H}$ functions. As one example, we used triethylammonium hydroxide $\left(\mathrm{Et}_{3} \mathrm{NHOH}\right)$ for $\mathrm{pH}$ adjustment, and observed significant increase of HER-activity, see Table 1. Based on the available data, this preliminary study suggests that ammonium cations which feature one $\left(\mathrm{Et}_{3} \mathrm{NH}^{+}\right)$or several $\left(\mathrm{NH}_{4}{ }^{+}\right)$ $\mathrm{N}-\mathrm{H}$ groups enhance the light-driven HER activity of the system studied.
As shown in Table 1, this HER-enhancing effect can be generalized and was observed when the solvent was varied from the protic polar methanol to the aprotic polar acetone (Figure $2 \mathrm{C}$ and Table 1, Entry 2). Variation of the $\mathrm{pH}$ from $\mathrm{pH} 6$ to $\mathrm{pH} 4$ does not affect the general trends observed (see Table 1, Entry 3 and Figure 2D). However, when using $\mathrm{Et}_{4} \mathrm{~N}$ at $\mathrm{pH} 4$, we still observe some HER activity ( $40 \%$ lower compared to the use of $\mathrm{NH}_{4}{ }^{+}$, Figure 2D). In contrast, at $\mathrm{pH} \mathrm{6}$, the HER evolution difference between $\mathrm{Et}_{4} \mathrm{~N}^{+}$and $\mathrm{NH}_{4}{ }^{+}$was much larger (Figure $2 \mathrm{~A}$ ). In the presence of $\mathrm{Et}_{4} \mathrm{~N}^{+}$, HER-activity is reduced by $~ 96 \%$ (based on TONs) compared with the $\mathrm{NH}_{4}{ }^{+}$-containing system. This indicates that the observed effect is controlled by proton concentration in solution.
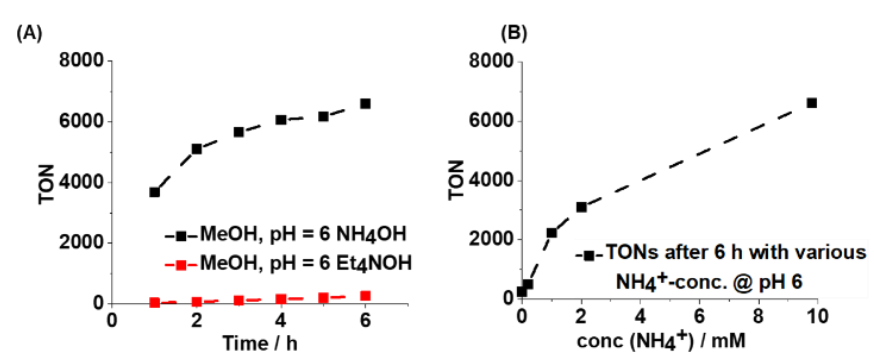

(C)
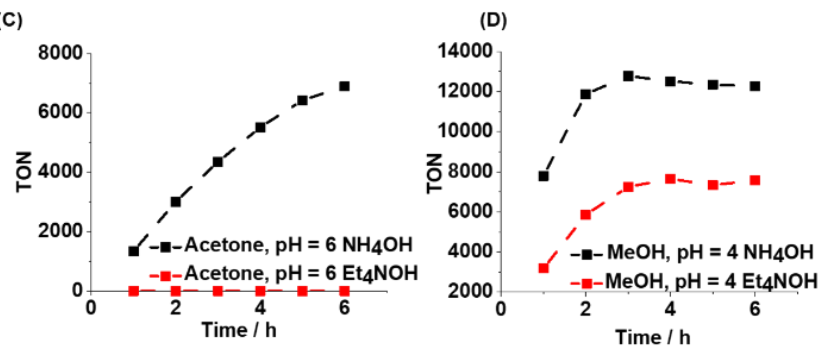

Figure 2: Turnover numbers (TONs) over time. (A) In methanol:water 9:1 (v:v) at $\mathrm{pH}=6$ adjusted with aqueous $\mathrm{NH}_{4} \mathrm{OH}$ or $\mathrm{NEt}_{4} \mathrm{OH}$ solution, (C) in acetone: water 9:1 (v:v) at pH=6 adjusted with aqueous $\mathrm{NH}_{4} \mathrm{OH}$ or $\mathrm{NEt}_{4} \mathrm{OH}$ solution, (D) in methanol:water 9:1 (v:v) at $\mathrm{pH}=4$ adjusted with aqueous $\mathrm{NH}_{4} \mathrm{OH}$ or $\mathrm{NEt}_{4} \mathrm{OH}$ solution, (B) dependency of TONs on $\mathrm{NH}_{4}{ }^{+}$concentration after $6 \mathrm{~h}$ irradiation. Conditions: [Ru-PS] $=20 \mu \mathrm{M},[\mathrm{CAT}]=0.3 \mu \mathrm{M}$, [SED] $=10 \mathrm{mM}$.

Table 1. HER activity in the presence of different ammonium cations, based on turnover numbers for the model reaction system Ru-PS, $\left\{\mathrm{Mo}_{3}\right\}$, ascorbic acid/ascorbate ${ }^{\mathrm{a}}$

\begin{tabular}{|c|c|c|c|c|c|}
\hline No & Solvent ${ }^{a}$ & $\mathrm{pH}$ & $\mathrm{NH}_{4}{ }^{+}$ & $\mathrm{Et}_{4} \mathrm{~N}^{+}$ & $\mathrm{Et}_{3} \mathrm{NH}^{+}$ \\
\hline 1 & Methanol : $\mathrm{H}_{2} \mathrm{O}$ & 6.0 & 6605 & 260 & 6411 \\
\hline 2 & Acetone : $\mathrm{H}_{2} \mathrm{O}$ & 6.0 & 6897 & 0 & 1353 \\
\hline 3 & Methanol : $\mathrm{H}_{2} \mathrm{O}$ & 4.0 & 12269 & 7571 & 9381 \\
\hline 4 & Acetone : $\mathrm{H}_{2} \mathrm{O}$ & 4.0 & 6217 & 2925 & 4634 \\
\hline
\end{tabular}

a $[$ Ru-PS $]=20 \mu \mathrm{M}, \quad\left[\left\{\mathrm{Mo}_{3}\right\}\right]=0.3 \mu \mathrm{M}, \quad$ [ascorbic acid/ascorbate $]=10 \mathrm{mM}$, solvent mixture: solvent: $\mathrm{H}_{2} \mathrm{O}(9: 1, \mathrm{v}: \mathrm{v})$; tirradiation $=6 \mathrm{~h}$.

To explore whether the observed HER enhancement by ammonium is linked to PS or CAT, we systematically varied both species. First, we replaced the original CAT, $\left\{\mathrm{Mo}_{3}\right\}$ and used the literature-known cobaloxime HER CAT [Co(dmgH $\left.)_{2} \mathrm{PyCl}\right]$. Here, we also observed drastically increased HER performance in the presence of ammonium ions, see Figure 3A. This suggests that the HER-enhancing effect is not limited to one specific HER-CAT type and can be used for a range of different metal complex HER-CATs. In addition, the data suggest that the effect is most likely related to the PS-based reaction steps. 

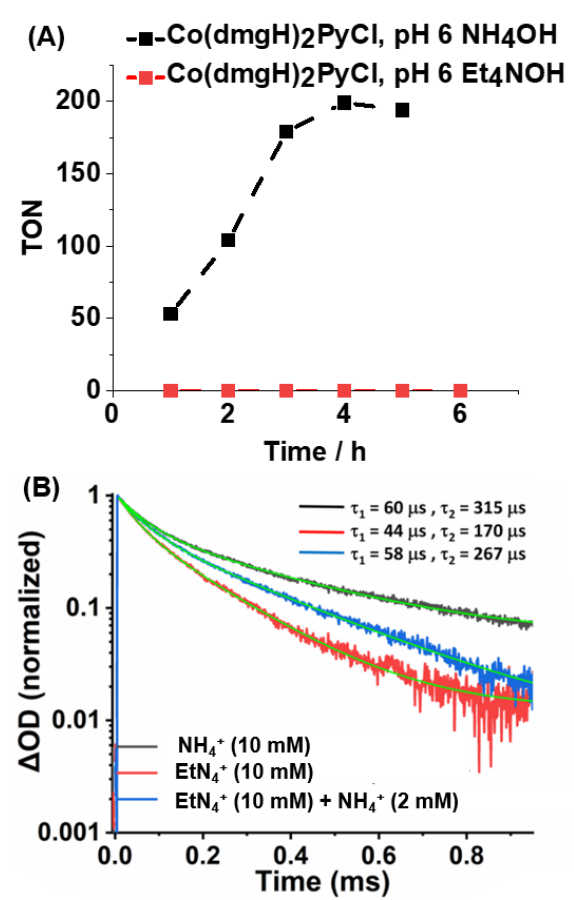

Figure 3: (A) Turnover numbers (TON) over time using cobaloxime ([Co( $\mathrm{dmgH}) 2 \mathrm{PyCl}]$ ) as HER catalyst. Conditions: [Ru-PS] $=20 \mu \mathrm{M}$, [CAT] $=4 \mu \mathrm{M}$, [ascorbic acid/ascorbate] $=10 \mathrm{mM}, \mathrm{MeOH}$ : water 9:1 (v:v), (B) decay kinetics for reduced $\left[\mathrm{Ru}(\mathrm{bpy})_{3}\right]^{+}$in the presence of $\mathrm{NH}_{4}{ }^{+}$or $\mathrm{EtN}_{4}{ }^{+}$, or a mixture thereof (no catalyst present).

To explore this hypothesis, we performed femtosecond ( $\mathrm{fs}$ ) and nanosecond (ns) transient absorption (TA) spectroscopy on RuPS in the presence of ammonium as well as tetraethyl ammonium ions (and the SED) to rationalize our observations from the catalytic experiments described above. Photoexcitation of Ru-PS in presence of the SED (ascorbic acid/ascorbate) led to the formation of reduced Ru-PS (i.e. $\left.\left[\mathrm{Ru}(\mathrm{bpy})_{3}\right]^{+}\right)$, as detected in fs-TA measurements by the characteristic absorption at $510 \mathrm{~nm}$ (ESI, Figure S6). ${ }^{29}$ This longlived feature decays on a $\mu s$ - ms timescale, as probed by ns-TA. These studies revealed changes in the photophysical behaviour of Ru-PS, depending on the presence or absence of $\mathrm{NH}_{4}{ }^{+}$, see Figure 3B. Specifically, the lifetime of the reduced Ru-PS'approximately doubles in the presence of ammonium ions $(10 \mathrm{mM})$. In contrast to earlier reports on Ru-PS ${ }^{-}$in a DMF/sodium ascorbate system, ${ }^{30}$ we observed a bi-exponential decay, in the presence of ammonium or tetraethyl ammonium (Figure 3B). This observation is tentatively assigned to the presence of oxidised SED, which is known to act as an efficient quencher for the reduced Ru-PS ${ }^{-2} .20$ this could lead to two independent decay pathways, i.e. a geminate- and nongeminate-like decay. Analysis of the fs kinetics, which represent the reductive quenching of the photoexcited Ru-PS, indicates no observable effect of $\mathrm{NH}_{4}{ }^{+}$or $\mathrm{EtN}_{4}{ }^{+}$(Figure S7). This suggests that the formation of the reduced Ru-PS ${ }^{--}$is not affected by the presence these ions. Nonetheless, the increased lifetime of the reduced photosensitizer is generally considered beneficial for HER catalysis and could be one major contributor to the observed HER-activity increase. In addition, the lifetime of the reduced $\mathrm{Ru}^{-\mathrm{PS}^{-}}$increases with increasing ammonium concentration, emphasizing that the concentration-dependent effect of ammonium on the HER activity (Figure 2B) could be due to increased lifetimes of the Ru-PS under the catalytic conditions studied. To the best of our knowledge, this behaviour has not been reported previously.

To assess whether this reactivity is specific to $\left[\mathrm{Ru}(\mathrm{bpy})_{3}\right]^{2+}$, we performed additional catalytic experiments under the conditions described above, where the original Ru-PS was exchanged for structurally related $\mathrm{Ru}$ - or Ir-based photosensitizers. As shown in Table 2, in all cases studied, the HER-enhancing activity of ammonium was observed, and increase of $\mathrm{H}_{2}$ evolution (under otherwise identical reaction conditions) by factors up to $>30$ was observed.

Finally, we hypothesized that the ammonium ions might be interacting with the SED (ascorbic acid/ascorbate), as electrostatic as well as hydrogen bonding interactions between both species are possible. To explore whether the observed HER-enhancement is specific for ascorbic acid/ascorbate, we performed a reference experiment where N-benzyl-1,4dihydronicotineamide (BNAH) is used as alternative SED (using Ru-PS and $\left\{\mathrm{MO}_{3}\right\}$ as PS and CAT, respectively), see Table 2. This study also showed increased light-driven HER activity, however, here, the observed increase in $\mathrm{H}_{2}$ evolution was only a factor $\sim 2.5$.

Table 2. Turnover numbers after $4 \mathrm{~h}$ with different PS or SED

$\begin{array}{lll} & \mathbf{N H}_{4}{ }^{+} & \mathbf{E t}_{4} \mathbf{N}^{+} \\ \text {PS: } & 1052 & 31 \\ \left.\text { [Ru(tertbutyl-bpy) })_{3}\right]^{2+} & (10 \mathrm{mM}) & (10 \mathrm{mM}) \\ \text { PS: } & 1509 & 44 \\ \text { [Ir(ppy) }_{2}(\text { bpy) }]^{+} & (10 \mathrm{mM}) & (10 \mathrm{mM}) \\ \text { SED: } & 610 & 256 \\ \text { BNAH } & (5 \mathrm{mM}) & (10 \mathrm{mM})\end{array}$

conditions: $[\mathrm{PS}]=20 \mu \mathrm{M},\left[\left\{\mathrm{Mo}_{3}\right\}\right]=0.3 \mu \mathrm{M},[\mathrm{SED}]=10 \mathrm{mM}$.

In sum, we report the surprising HER-enhancing effect of $\mathrm{NH}_{4}{ }^{+}$ cations when used with a range of metal complex photosensitizers and metal-based molecular HER catalysts. Initial studies show that the enhancing effect is not limited to a specific type of photosensitizer, catalyst or electron donor, and preliminary photophysical studies indicate that changes to the photophysical properties of the model PS studied might be one of the reasons for the observed reactivity increase. Other possible mechanisms which could contribute significantly to the observed reactivity enhancement are electrostatic and hydrogen bonding effects, aggregation/ion pairing as well as proton-management by the ammonium ions. Subsequent studies will build on this initial explorative study and use insitu/operando experimental methods including time-resolved spectroscopies and spectro-electrochemistry together with computational analyses to rationalize the observed reactivity enhancement and provide in-depth understanding of which systems benefit most from the reactivity increase.

\section{Literature References}

1 N. S. Lewis, Science, 2007, 315, 798-801.

2 J. Barber, Chem. Soc. Rev., 2009, 38, 185-196.

3 T. N. Veziroğlu and S. Şahin, Energy Convers. Manag., 2008, 49, 1820-1831. 

67.

M. Grätzel, Nature, 2001, 414, 338.

Z. Wang, C. Li and K. Domen, Chem. Soc. Rev., 2019, 48, 2109-2125.

M. Kirch, J.-M. Lehn and J. Sauvage, Helv. Chim. Acta, 1979,

62, 1345-1384.

J. M. LEHN, J. P. Sauvage and S. JP, Nouv. J. Chim., 1977, 1, 449-451.

D. Streich, Y. Astuti, M. Orlandi, L. Schwartz, R. Lomoth, L. Hammarström and S. Ott, Chem. - A Eur. J., 2010, 16, 6063.

F. Wang, W.-G. Wang, H.-Y. Wang, G. Si, C.-H. Tung and L.Z. Wu, ACS Catal., 2012, 2, 407-416.

T. R. Simmons, G. Berggren, M. Bacchi, M. Fontecave and V. Artero, Coord. Chem. Rev., 2014, 270-271, 127-150.

M. Watanabe, Y. Honda, H. Hagiwara and T. Ishihara, J. Photochem. Photobiol. C Photochem. Rev., 2017, 33, 1-26. J. Willkomm and E. Reisner, Bull. Japan Soc. Coord. Chem., 2018, 71, 18-29.

V. Artero, M. Chavarot-Kerlidou and M. Fontecave, Angew. Chemie - Int. Ed., 2011, 50, 7238-7266.

J. Jökel, F. Schwer, M. von Delius and U.-P. Apfel, Chem. Commun., 2020, 56, 14179-14182.

M.-L. Grutza, A. Rajagopal, C. Streb and P. Kurz, Sustain. Energy Fuels, 2018, 2, 1893-1904.

P. D. Tran, T. V. Tran, M. Orio, S. Torelli, Q. D. Truong, K. Nayuki, Y. Sasaki, S. Y. Chiam, R. Yi, I. Honma, J. Barber and V. Artero, Nat. Mater., 2016, 15, 640-646.

J. Barber and P. D. Tran, J. R. Soc. Interface, 2013, 10, 20120984-20120984.

D. Ziegenbalg, A. Pannwitz, S. Rau, B. Dietzek-Ivanšić and C. Streb, .

E. Deponti, A. Luisa, M. Natali, E. lengo and F. Scandola, Dalt. Trans., 2014, 43, 16345-16353.

C. Bachmann, B. Probst, M. Guttentag and R. Alberto, Chem. Commun., 2014, 50, 6737-6739.

A. Reynal, E. Pastor, M. A. Gross, S. Selim, E. Reisner and J. R. Durrant, Chem. Sci., 2015, 6, 4855-4859.

R. Gueret, C. E. Castillo, M. Rebarz, F. Thomas, M. Sliwa, J. Chauvin, B. Dautreppe, J. Pécaut, J. Fortage and M. N. Collomb, Inorg. Chem., 2019, 58, 9043-9056.

S. Chakraborty, E. H. Edwards, B. Kandemir and K. L. Bren, Inorg. Chem., 2019, 58, 16402-16410.

B. B. Beyene and C. H. Hung, Sustain. Energy Fuels, 2018, 2, 2036-2043.

6 R. S. Khnayzer, V. S. Thoi, M. Nippe, A. E. King, J. W. Jurss, K. A. El Roz, J. R. Long, C. J. Chang and F. N. Castellano, Energy Environ. Sci., 2014, 7, 1477-1488.

27 A. Rajagopal, F. Venter, T. Jacob, L. Petermann, S. Rau, S. Tschierlei and C. Streb, Sustain. Energy Fuels, 2019, 3, 9295. M. Dave, A. Rajagopal, M. Damm-Ruttensperger, B. Schwarz, F. Nägele, L. Daccache, D. Fantauzzi, T. Jacob and C. Streb, Sustain. Energy Fuels, 2018, 2, 1020-1026. C. Creutz and N. Sutin, J. Am. Chem. Soc., 2002, 98, 63846385.

0 S. Montanaro, C. Herrero, D. Merli, M. Fagnoni, A. Poggi, S.
Protti, S. Sheth and A. Albini, Green Process. Synth., 2013, 2, 335-343. 